\title{
The Use of Augmented Reality in Retail: A Review of Literature
}

\author{
Marc Riar \\ IKM, Technical \\ University of Berlin \\ marc.riar@tu-berlin.de
}

\author{
Jakob J. Korbel \\ IKM, Technical \\ University of Berlin \\ jakob.j.korbel@tu-berlin.de
}

\author{
Nannan Xi \\ Gamification Group \\ Tampere University \\ nannan.xi@tuni.fi
}

\author{
Rüdiger Zarnekow \\ IKM, Technical \\ University of Berlin \\ ruediger.zarnekow@tu-berlin.de
}

\author{
Juho Hamari \\ Gamification Group \\ Tampere University \\ juho.hamari@tuni.fi
}

\begin{abstract}
Novel digital technologies are affording ways to superimpose perceptual information (be it auditory, visual, haptic or olfactory) onto our reality, e.g. in retail environments. These technologies that aim to enhance reality are generally called Augmented Reality (AR) technologies. Today, the field of research focused on $A R$ retail has evolved to mature enough state that an overview of the state-of-the-art, results and ways in which AR has been employed in research is needed. Therefore, in this study we conduct a systematic literature review of the academic corpus focused on AR retail. We report on how and where AR is employed in retail, what technological characteristics of AR are commonly analyzed as well as what potential psychological and behavioral outcomes AR is capable of evoking. Overall, AR is a technology with high potential for in-store and remote (online) shopping in terms of evoking both utilitarian and hedonic experiences.
\end{abstract}

\section{Introduction}

Augmented reality has been a prominent technology trend during the last ten years. While the increasing maturity of the AR technology already lead to a distinct usage in industries such as gaming, for example Pokémon Go [e.g. 17, 29], and the educational context [e.g. 7, 50], prominent examples of its application in online retail are sparse. Traditional web-based online retail still has limitations in terms of product presentation, inability to try products, information richness and multidimensional experientiality. For example, when assessing large furniture and products with high economic values, consumers often end up going to physical stores in order to acquire a more multifaceted understanding of the product in order to minimize risk. The popularity of mobile devices and the advent of immersive technology [47, 51] such as AR (augmented reality) are believed to provide new opportunities for increasing multimodality, richness of information and place independency of retail [19, 26]. In a few XR (extended reality) related studies, VR (virtual reality) and AR are sometimes used interchangeably, however, whereas virtual reality refers to substituting the perceived reality $[8,20], \mathrm{AR}$ refers to augmenting the perceived reality $[11,16]$. Therefore, AR technologies sense multiple types of information from the surrounding of the user and use multimodal and multisense (haptics, vision, audio, olfactory etc.) technologies to augment the experience of reality $[2,14]$, be it in relation to adding cognitive, affective, or social affordance.

Currently, several international retail companies such as IKEA, Walmart and Amazon have developed their own AR applications to supplement the current retail activities. In addition, a few "hyper" AR wearables facilitate consumers' shopping experience via e.g. hands free, less response time and rich interaction. However, retailers and business practitioners do not seem to have full confidence in the future of augmented retail due to its unknown influence on business performance as well as consumer acceptance, and hence, there has been a growing research interest in these matters lately [e.g. 3, 54]. As of yet, it is still unclear whether and how AR can provide inferior or superior consumer experience in retail environments and specifically in E-Commerce, that is the activity of electronically buying and selling products $[41,49]$.

To determine whether AR bears the potential of diffusion in retail, a holistic view on the effects and adoption mechanisms in the extant academic corpus is needed. Hence, the purpose of this paper is to synthesize the current empirical literature on AR in the context of retail in order to investigate how and where AR has been employed in retail, what is known about the effects and criteria for adoption and what potential directions for future research need to be further scrutinized. 


\section{Method}

The methodology of this paper is guided by recommendations for conducting systematic literature reviews by Kitchenham [28] and Brereton et al. [10]. In correspondence with these recommendations, we elucidate in this section the search strategy, study selection procedure and means of data extraction from the analyzed corpus of academic literature.

\subsection{Search strategy}

Brereton et al. [10] suggest that different bibliographic sources should be targeted for conducting an exhaustive search of literature. We decided to conduct the search within Web of Science and the Association for Information Systems Electronic Library (AISeL), as these databases index several additional bibliographic databases, such as the ACM Digital Library and IEEE Xplore. These databases cover a great spectrum of interdisciplinary fields and are highly recognized for comprising relevant literature from the realm of information systems and human-computer-interaction. Therefore, they seem adequate for exploring literature related to the outcomes and adoption of augmented reality.

We composed a search query which includes several different variations of the core search terms and we used asterisk $(*)$, in order to cover varying terminology in the literature (e.g. "AR" for augmented reality and "business", "commerce" in addition to retail). After an initial search, we added "virtual try-on" to the search query, as we found that several studies used this terminology in AR-based research. The final search query looks as follows:

\section{("augmented reality" OR AR OR "virtual try-on") AND (retail* OR commerce OR business)}

The search was performed in May 2020. In the Web of Science database, we executed the search query within the title, abstract as well as the keywords, and similarly, we performed the search in AISeL within the title, abstract and subject. We tested the appropriateness of the final search query by manually identifying several relevant publications and by then confirming that these publications were existent in the search result set. All manually identified relevant articles were found in the result set. Accordingly, we deemed the search query suitable and hence, no further refinements were made.

\subsection{Study selection}

The main inclusion criterion was that AR is analyzed in the context of retail (studies in other settings such as education, training etc. are excluded). In addition, it was important for inclusion that the studies are of empirical inferential nature (e.g. experiments, structural equation modelling etc.), as we are specifically looking at outcomes and the effectiveness of AR as well as factors that influence its adoption. Therefore, studies using other methodological approaches (e.g. case studies, design studies, empirical studies reporting only on descriptive results etc.) are excluded. The search result set contained a number of studies that analyzed virtual reality (VR). These studies were excluded, as we categorically focus on AR in this paper. The search considers literature between the years 2010 and May 2020. The cut-off year of 2010 was chosen because AR took a substantial leap in terms of its technological maturity and diffusion in the past decade and it can therefore be expected that the experience of using AR in more recent years is considerably different from the experience of using the technology more than ten years ago. As a final criterion for inclusion, we only considered peer reviewed articles (e.g. conference proceedings, journals and book chapters).

The study selection procedure is shown in Figure 1. In sum, the search query returned 581 publications from which we retrieved 568 (three publications that were not written in English and one duplicate were removed; the full texts of 9 articles were unavailable). In a successive step, we screened the titles, abstracts and conclusions of the remaining studies and excluded the ones that did not fit into our research scope. This trimmed our set of primary studies down to 59. Next, we analyzed the full texts of this remaining set and excluded another 35 studies (based on our inclusion / exclusion criteria stated above). In a final step, we analyzed the references from the included papers as well as papers which referenced our identified pool of studies. Through this forward and backward search, we were able to identify five additional studies, resulting in a final pool of 29 papers that are considered in this review (see Table 1).

Table 1: Final pool of reviewed literature

\begin{tabular}{|l|} 
Reviewed literature \\
[1], [4], [5], [9], [12], [15], [18], [19], [21], [22], [23], \\
[24], [25], [27], [31], [34], [35], [36], [38], [39], [40], \\
[41], [42], [44], [45], [48], [49], [52], [53]
\end{tabular}

\subsection{Data extraction}

Following the recommendation by Kitchenham [28] and Brereton et al. [10], we prepared a data extraction form. This form allowed us to gather and arrange all relevant information in an organized manner. It consists of a number of publication details (e.g. authors, title, year 
of publication, publication outlet etc.) and the relevant properties for this literature review (e.g. outcomes and effects of AR / possible criteria for adoption, theoretical concepts, information about the virtual products, how AR was employed and research design etc.). We randomly selected three different publications from our pool of primary studies and tested how well the form serves its purpose by extracting the relevant information. After some minor adjustments have been made to the form during its initial test, it was deemed suitable for the purpose of providing a well-structured way for extracting the necessary information from the publications.

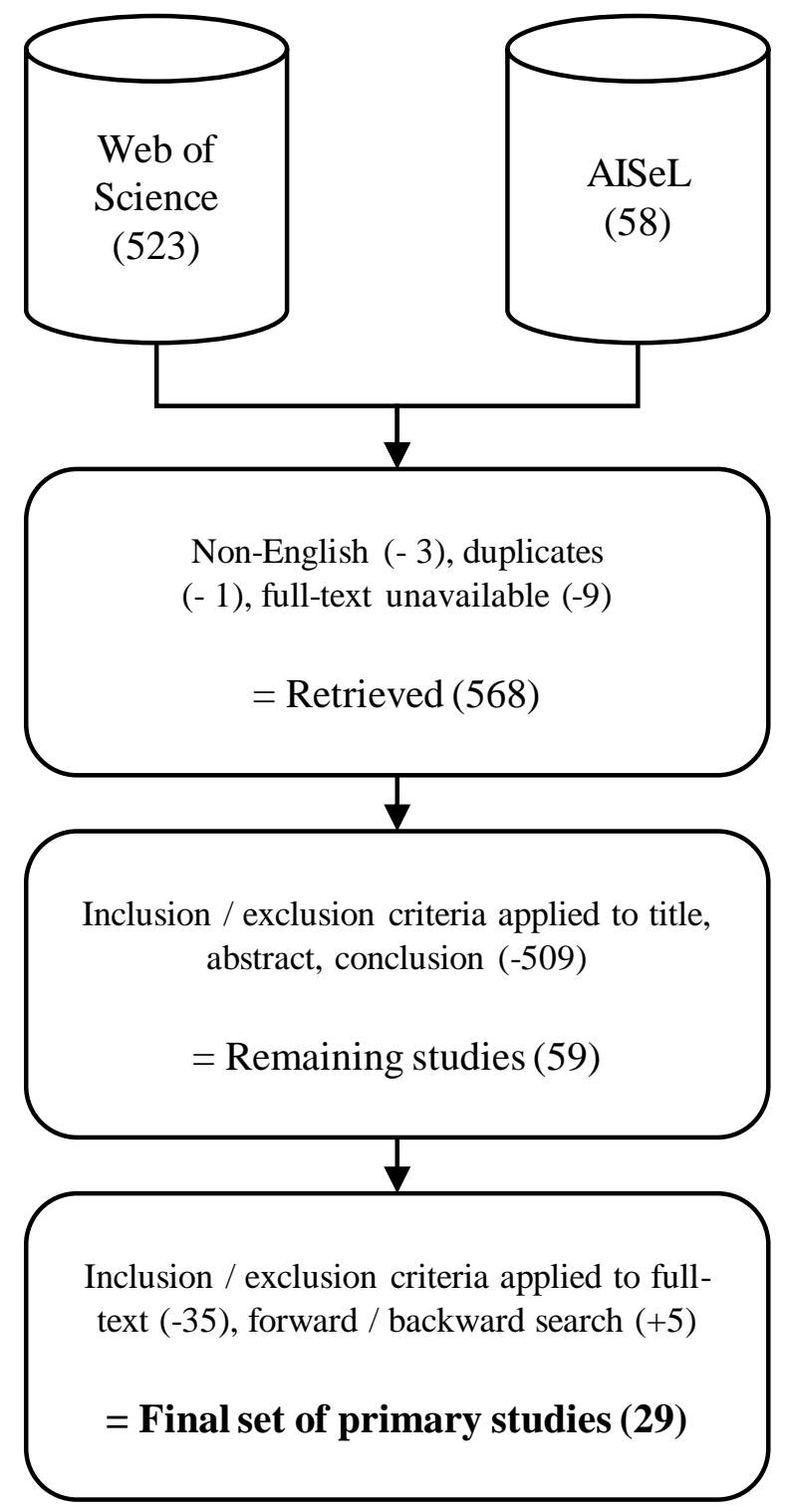

Figure 1: Study selection procedure

\section{Results}

\subsection{Where and how has AR been employed in retail?}

In the reviewed body of literature $(\mathrm{N}=29), A R$ is predominantly analyzed for the purpose of online retail (in $69 \%$ of the studies) (see Table 2). The purpose of online AR solutions is to provide users with unique product experiences and information without having to visit physical stores. The main advantage of online solutions consists in trying out products in any chosen surrounding and supporting users with purchase decisions $[1,9,15,31,38]$. In comparison to the significant number of studies that employed AR in online retail scenarios, only $17 \%$ of the analyzed studies chose to investigate in-store solutions of AR. Besides providing additional product information, in-store solutions may be used to attract customers to a brand and spark curiosity, thereby making the shopping experience within physical stores more engaging [27]. With regard to the applied research methodology, $76 \%$ of the reviewed articles conducted field studies or laboratory experiments, while the remaining $24 \%$ conducted survey research. When it comes to the devices, the reviewed studies largely relied on testing the effects of AR via the use of hand-based mobile devices, such as smartphones or tablets (59\%). The ability of AR to place virtual objects in a room and move them around seems to make the combination of using mobile devices in online retailing scenarios the preferable choice for the technology. On the other hand, a considerable number of the reviewed studies also relied on testing AR via desktop-PCs with web cameras in laboratory experiments (in $28 \%$ of studies). The participants were usually asked to view themselves in a situation using an AR application, which was then operated by the participants via the computer $[1,5]$. Some of these solutions also involve virtual mirrors where participants can see themselves and virtually try-on (e.g. fashion) products [e.g. 4, 22, 38]. Interestingly, only one study used specific head-based AR hardware (i.e. HoloLens) to assess the effects of AR in retail [i.e. 19]. However, since today's mobile devices have more advantages in terms of economic values, convenience, and low cost for developing AR features compared to special AR hardware that has hardly penetrated into regular households, it seems plausible that majority of studies analyze the effects of AR with more pervasive devices, such as mobile phones.

Regarding the types of products, it became apparent that wearable products, such as clothing, accessories, eyewear and cosmetic products are at the center of attention in the reviewed literature. The idea is that users are able to try on the virtual products and make an initial 
judgement of what the fashion or cosmetic products would look like on themselves, without actually having to try them on or even having access to the physical products. This phenomenon is referred to as virtual tryon and such AR solutions are commonly referred to as virtual or magic mirrors $[4,27,38,40]$. The second most encountered product categories used in the screened literature to study AR in retail are furniture and decorations. The notion with furniture and decorations is similar to that of clothes and makeup, namely that customers can get an idea of what the product will look like before buying it. In this case, customers can move around the furniture or decorations within the room it is intended for, and judge how the features of the piece (e.g. the color, size etc.) will fit into the room. More unique encounters have been food products, books and products of higher complexity, such as cars and technology (i.e. printers and laptops). It seems especially striking that high-complexity products played almost no role in the reviewed literature compared to products of lower complexity, such as clothing, accessories and furniture. High-complexity products usually have a lot of key features and require more information processing and evaluation. The study of Tarafdar et al. [48] indicates that the effectiveness of AR may vary depending of the type of product that is being virtually presented, however, such results need to be scrutinized further and thus it seems important that future research also explores more frequently to what extent AR solutions can support purchase decisions of high-complexity products.

Table 2: Overview of AR retail

\begin{tabular}{|l|l|l|l|}
\hline Environment & $\#$ & Presented Products & $\#$ \\
\hline Online web-based & 20 & Clothing, fashion, accessories, eyewear & 13 \\
\hline In-Store & 5 & Furniture, decorations & 9 \\
\hline Various / non-specific & 4 & Makeup, cosmetics & 6 \\
\hline Devices & $\#$ & Technology-related devices & 2 \\
\hline Hand-based mobile device (e.g. phone, tablet) & 17 & Food & 2 \\
\hline Desktop PC (with web camera) & 8 & Non-specific & 2 \\
\hline Magic / virtual mirror* & 5 & Books & 1 \\
\hline Non-specific & 3 & Cars & 1 \\
\hline Head-based AR hardware (HoloLens) & 1 & & \\
\hline *Virtual mirrors were usually realized via PCs with & \multicolumn{2}{|l}{ camera or via tablets } & \\
\hline
\end{tabular}

\subsection{What are the effects of using AR?}

All of the reviewed articles reported generally positive oriented results and support the effectiveness of AR in retail (minority of studies reported on mixed results and none of the studies exclusively reported negative outcomes). The studies often analyzed how AR performs compared to non-AR configurations to give rise to psychological (see Table 3) or behavioral outcomes (see Table 4) [e.g. 5, 9, 23, 25, 35, 44, 48, 52], as well as how specific AR characteristics (see Table 5) influence psychological and behavioral outcomes [e.g. 15, $18,19,22,34,38]$. As presented in Table 4, our literature review reveals that most studies were concerned with investigating the effects of AR on behavioral intentions to purchase products $[1,4,9,25,27,36,38,39$, $44,52,53]$, intentions to use or reuse an AR app [25, 42,
45] as well as intentions to recommend the AR app to others [18, 21, 22, 25, 27, 39]. Naturally, these outcomes are preceded by psychological experiences and when we turn our attention to these psychological facets of using $\mathrm{AR}$, it becomes apparent that both cognitive and affective outcomes played a major role in the reviewed body of literature (refer to Table 3). From a cognitive viewpoint, we found that the most established variables have been perceived usefulness and perceived ease of use, which together with attitude represent the core of wellestablished adoption theories, most prominently the technology acceptance model (TAM) [13]. The analyzed literature chiefly confirms the explanatory power and the tenacity of the TAM to determine the adoption of AR in retail [24, 34, 38, 39, 42, 45]. However, it is also evident that the adoption of AR technology relies on further considerations and cannot fully be explained by the components of the TAM. Especially cognitive 
theories such as cognitive load theory, cognitive theory of multimedia learning, mental elaboration and cognitive fluency theory have been employed in the reviewed studies to help explain the adoption and effects of AR $[15,21,22,39,48]$. Interestingly, the reviewed literature reveals a certain level of ambivalence in regard to the ease of use and cognitive exertion of AR. On the one hand, Lu and Smith [31] found that a conventional nonAR solution was perceived as easier to use in contrast to an AR solution while Tarafdar et al. [48] found that AR interfaces burden users with heightened cognitive load as compared to traditional product presentations. One possible explanation for the high cognitive load is that users in augmented reality usually have to process the information more both in the physical and virtual world. On the other hand and in contradiction to this, several studies found that AR has the ability to reduce users' cognitive load and enhance users' cognitive fluency via vivid and interactive product presentations that support the mental effort of imagining a product, which in turn can result in positive attitudes [15, 39], increased decision comfort [18, 19], willingness to pay [19] and purchase intentions [15]. These findings suggest that AR research needs to continue to employ cognitive theories and investigate in more detail how and under what circumstances AR technology may support or impair the cognitive effort of consumers.

From the affective perspective, especially the hedonic value (i.e. enjoyment) has been the most prevailing in the reviewed body of literature (encountered in 52 $\%$ of the studies). It was found that the presence of and interaction with AR can enhance the hedonic experience (e.g. fun, entertainment, playfulness and enjoyment) in stores or retailing apps $[5,12,22,27,34,38,41,44,52$, 53]. The reviewed literature provides significant support that the hedonic experiences afforded by AR can enhance store attractiveness [5], positive attitudes [38, 44], satisfaction, brand engagement [34], willingness to share personal information [44], purchase intentions $[27,41,52,53]$ as well as intentions to return to the AR app and word of mouth intentions [27]. These results highlight that aside from the cognitive determinants, affective outcomes can be a major driving force for the adoption of AR, of which above all the hedonic experience is of significance.

Moreover, AR-based retail can also influence different social aspects and other psychological states (mainly personality related). See Table 3 below for more details.

In addition to investigating the effects of using AR in general, the reviewed body of literature examined, commonly as independent variables, how different specific technological characteristics of AR affect individuals during retail (see Table 5). In the extant literature, AR has been widely considered to have three key characteristics, namely interactivity, vividness and novelty
[2]. The most frequently analyzed affordances in the reviewed literature were related to the interactivity of AR technology (e.g. simulated physical control, sensory control, high vs. low degrees of transformation capabilities etc.). Interactivity is understood as the degree to which users can modify objects in a mediated surrounding in real time [46], and it seems not surprising that it is one of the key affordances analyzed in AR research considering that one of the main benefits for users of the technology consists in the ability to interact with virtual objects. According to the reviewed literature, affordances related to interactivity can enhance, among other factors, users' perceived ease of use [38], value perceptions [22], cognitive fluency, attitudes towards products [15] and brand engagement [23, 34].

The second most encountered AR characteristics in the screened literature have to do with the representation of the augmented environment (e.g. the vividness, environmental embedding, or AR imagery configuration). Vividness refers to the representational richness of a medium and together with interactivity, it is considered to affect the human experience of immersion [46]. Several of the reviewed studies provide empirical support for this notion [22, 48, 52]. Other possible outcomes of vividness encountered in our review entail higher perceptions of enjoyment, ease of use and usefulness [e.g. $34,52]$. One issue to consider is that the effects of $A R$ may vary depending on the degrees of interactivity and vividness that is being achieved by the technology. For example, Heller et al. [18] offer that AR configurations may vary from low imagery configurations (e.g. static pictures of products) to high imagery configurations (e.g. interactive 3D products). These different configurations can affect users' mental processing in so far that high imagery configurations of AR enable users to offload mental imagery better than lower degrees of imagery configurations, which ultimately exploits the advantages of AR more saliently [18].

In addition to interactivity and vividness, the novelty of AR is considered to be a significant aspect of AR [52]. Novelty can be described as the newness or uniqueness of a stimuli [33] and the screened literature reveals that similarly to interactivity and vividness, novelty may give rise to higher perceptions of enjoyment, usefulness [34] as well as brand engagement [52]. However, it was also found to be an ineffective attribute [e.g. 49] and that with increased experience with the medium, novelty effects are likely to wear off [52]. It is also worth mentioning that compared to interactivity and vividness, novelty of AR has been encountered only sparingly in the reviewed body of literature and it is likely that this has to do with the fact that in recent years, AR has become more and more ubiquitous and hence, the innovativeness of the technology has become less of a focal point in AR research. Due to the increasing maturity of 
the technology, the same may be true for performance related aspects of $\mathrm{AR}$, such as the responsiveness, which has been considered in only three of the analyzed studies $[25,38,39]$. Whereas aspects of novelty and performance seem to fade into the background in AR research, it appears that certain utilitarian characteristics of the technology are gaining momentum, such as the quality and extent of informativeness. While AR naturally provides relevant cues about products via possibilities of trying out and interacting with them virtually, some selected studies also indicate that informativeness can further be increased via affordances that allow for point-ofview sharing between customers [21] or via customer recommendations within AR environments [1]. The increased informativeness and information quality may positively affect perceived usefulness as well as product fit uncertainties and eventually support decision making $[1,38]$. Especially in the context of retail, it seems important that the expectations of customers to be informed about a product are met with high quality information [40], and it therefore seems important that future research continues to address this issue. Specifically, it seems crucial to gain a better understanding about how enhancing AR product presentations with additional information (e.g. star ratings etc.) can benefit the informativeness of users while at the same time considering potential drawbacks, such as cognitive overexertion of customers.

Table 3: Psychological outcomes

\begin{tabular}{|c|c|c|c|}
\hline Cognitive / overall usage perceptions & \# & Affective & \# \\
\hline Perceived usefulness / pragmatic / utilitarian & 12 & Enjoyment / playfulness / hedonic value & 15 \\
\hline Perceived ease of use / usability & 8 & Attitude / overall evaluation & 12 \\
\hline $\begin{array}{l}\text { Cognitive load, cognitive processing fluency, cogni- } \\
\text { tive innovativeness, mental elaboration, mental in- } \\
\text { tangibility }\end{array}$ & 7 & Satisfaction & 5 \\
\hline Perceived aesthetics / store attractiveness & 4 & Immersion / Presence & 4 \\
\hline Product fit uncertainty / product risk perceptions & 4 & Decision comfort & 3 \\
\hline Perceived privacy risk / intrusiveness & 2 & Discomfort / aversive effects & 2 \\
\hline Perceived informativeness & 2 & Flow & 1 \\
\hline Perceived ownership / sense of ownership control & 2 & Brand love & 1 \\
\hline Perceived controllability / (User's control) & 2 & Desire for product & 1 \\
\hline Perceived augmentation & 2 & $\begin{array}{l}\text { Other psychological states / personality } \\
\text { related }\end{array}$ & $\#$ \\
\hline Perceived product usage barriers & 1 & Style of processing / processing type & 2 \\
\hline Trade-off between price and value & 1 & Confidence level & 1 \\
\hline Social & \# & Curiosity & 1 \\
\hline Perceived socialization & 1 & Self-referencing & 1 \\
\hline Subjective norms & 1 & IT identity & 1 \\
\hline \multirow[t]{2}{*}{ Social empowerment } & 1 & Familiarity with AR & 1 \\
\hline & & Quality of mental imagery & 1 \\
\hline
\end{tabular}


Table 4: Behavioral outcomes

\begin{tabular}{|l|l|l|l|}
\hline Engagement & $\#$ & Miscellaneous & $\#$ \\
\hline Purchase intention, willingness to pay buy / pay & 17 & Intention to recommend / WOM intention & 6 \\
\hline Intention to use / reuse AR app / revisit AR store & 8 & $\begin{array}{l}\text { User's control of access to personal information / } \\
\text { willingness to share personal data / awareness of } \\
\text { privacy practices }\end{array}$ & 4 \\
\hline Brand engagement / brand usage intention & 2 & Convenience of the transaction & 2 \\
\hline & & User preference & 1 \\
\hline
\end{tabular}

Table 5: AR technology characteristics

\begin{tabular}{|l|l|l|l|}
\hline AR attributes & $\#$ & Quality / performance & $\#$ \\
\hline $\begin{array}{l}\text { Interactivity, simulated physical control, rehearsa- } \\
\text { bility, sensory feedback and control / self-empow- } \\
\text { erment, transformation }\end{array}$ & 9 & $\begin{array}{l}\text { Vividness, environmental embedding, AR im- } \\
\text { agery generation / configuration, mapping qual- } \\
\text { ity }\end{array}$ & 6 \\
\hline Novelty / Innovativeness & 3 & Response time / responsiveness & 3 \\
\hline Anthropomorphism & 1 & Service excellence & 1 \\
\hline Informativeness & $\#$ & & \\
\hline Information provided, information quality & 3 & & \\
\hline $\begin{array}{l}\text { Recommendations, communicate acts, point-of- } \\
\text { view sharing }\end{array}$ & 3 & & \\
\hline Product contextuality / complexity & 2 & & \\
\hline
\end{tabular}

\section{Discussion}

This review provides an overview and synthesis of empirical literature on AR in retail. Based on careful review of 29 studies, we report on how and where AR is employed in retail, what technological characteristics of AR are commonly analyzed as well as what potential psychological and behavioral outcomes AR is capable of evoking.

The findings of this review indicate that $A R$ is an effective technology for both in-store and remote shopping experiences in the sense that it can support mental intangibility of consumers via vivid product presentations and interaction possibilities that can give rise to a number of different cognitive and affective as well as behavioral outcomes. In particular, the literature reveals that AR can evoke utilitarian and hedonic experiences, which are both significant driving forces for the adoption of AR in retail.

The utilitarian evaluation stems from the technological abilities of AR such as the vivid depictions of products as well as the interactivity, by which users can manipulate the virtual products and thereby experience, for example, enhanced cognitive support $[15,18]$, immersion and informativeness [34, 42, 52]. Essentially, AR can reduce uncertainties and product risk perceptions [5, 48], thereby assisting consumers with their purchase decisions. The reviewed literature was mostly concerned with mobile solutions for online retail, whereas in-store solutions played an inferior role. However, AR has been found to be effective in both scenarios. Nevertheless, the usefulness of AR is arguably exploited more effectively in online retail where users have no access to the physical products but find that via AR, they can still gain unique insights that can increase decision comfort. The hedonic experience was found to be similarly important. The use of AR is largely perceived as entertaining and enjoyable, which can affect perceived store attractiveness [5], brand engagement [34, 44], intentions to visit the online store [5] and intentions to recommend it to others [22, 27].

\section{1 Practical implications and future research}

With regard to some of the encountered gaps and challenges within the reviewed body of literature, we 
identified some recommendations for business practitioners, AR designers and possible matters for future research. To begin with, there have been results that indicate that AR can negatively affect cognitive effort of consumers while there have also been indications that AR can in fact help reduce cognitive load. Evidently, AR research needs to continue to delve into cognitive theories and investigate how and under what conditions AR technology may support or agitate different dimensions of cognitive effort of consumers (e.g. NASATLX-six dimensions of workload). Arguably, this may depend on the interface design and number of functions of the AR solution on the one hand, and on the type of product that is virtually presented on the other. With regards to the interface design, we can expect that AR solutions will continue to become more complex in terms of their features and additional visual information. One intriguing direction for retailers and designers should be to enhance AR product presentations with customer reviews. Considering that a major utilitarian benefit of online retailing portals is the availability of customer reviews, it is surprising that these are rarely available while products are being viewed as $3 \mathrm{D}$ representations in AR applications. Instead, users are usually forced to "leave" the AR-view to explore customer reviews, resulting in inconvenient controls due to permanent switching between product representations and customer reviews, which greatly inhibits the usability of AR applications. Therefore, practitioners should explore possibilities to embed product reviews (e.g. star ratings) within the $\mathrm{AR}$ product presentation while research needs to explore how these additional information may enhance the utilitarian value of AR in retail but also if the cognitive load of these additional information is still tolerable for the consumers.

As mentioned above, the type of product may also play a role for the invested cognitive effort, especially in terms of the complexity. From our review, the study by Tarafdar et al. [48] stands out in this matter, as it is the only one to compare how low and high-complexity products fare in AR applications. Their results indicate that product risk perceptions can be more significantly lowered, and satisfaction more significantly increased for high-complexity products, while against their expectations, there was no significant difference in terms of cognitive load between low and high-complexity products. However, it is clear that such results need further scrutiny. Holistically speaking, this review illustrates that empirical AR research on high-complexity products (e.g. technology products) is meager compared to products of lower complexity, such as fashion and furniture. One explanation could be that high-complexity products demand more of AR solutions in order to sufficiently provide information to the consumer and ultimately support purchase decision. However, with the increasing technological maturity of AR, current and future solutions should be well-equipped to provide more elaborate augmentations and novel ways to virtually interact with high-complexity products. Therefore, it seems an important future waypoint to explore more frequently to what extent AR solutions can support purchase decision of high-complexity products, while the tradeoff between the usefulness of AR for such products and possible drawbacks concerning cognitive overexertion should not be neglected. A further potential direction could be to explore more frequently how the experience level of users with AR affects their cognitive effort while engaging with the technology (e.g. via longitudinal studies).

Last but not least, we found that affective responses, especially regarding the hedonic experiences from using the technology is similarly important as the cognitive and utilitarian aspects in retail. AR is largely perceived as entertaining and enjoyable, which accounts for a great proportion of the use and reuse of the technology as well as intentions to recommend it to others. Hedonic perceptions may especially stem from the novelty and innovativeness of AR, however, one encountered issue pertaining to this is that novelty effects wear off with increased experience with AR. AR has matured in the past decade and has become increasingly pervasive. Mobile devices are increasingly rolled-out with AR capabilities, and AR features can now largely be found in everyday activities such as educational contexts [e.g. 7, 50], in the workplace [e.g. 6, 32] and in numerous leisure applications, perhaps most prominently in games [e.g. 17, 29, 30, 37, 43]. Due to the now seemingly extensive familiarity with the technology, perhaps we have reached a stage in which we need to reconsider what novelty stands for in $\mathrm{AR}$ and on the basis of what technological virtues or alternative proficiencies we operationalize novelty in future AR-based research. With regard to our review, the study by Yim et al. [52] yields a considerable foothold for this argument, indicating that previous experience with AR results in diminished novelty perceptions. In order to rejuvenate the innovativeness of AR in retail and to ensure that consumers keep experiencing hedonic perceptions, AR applications and future research are encouraged to veer towards various contemporary directions. In the extant literature, it can be noticed that AR has mainly provided access to additional visual information (the product). The multi-sensory experience can also be enhanced by providing augmenting graphics, text, videos, sounds, or other virtual elements, which require more future research. In addition, some further promising directions could involve but are not limited to exploring the use of gamification, immersive technologies, artificial intelligence and spatially aware approaches in AR-supported retailing applications. 


\subsection{Limitations}

This review is limited to literature of empirical nature and studies that investigated AR in the specific context of retail. Therefore, literature that examines AR in other contexts as well as concepts adjacent to AR (e.g. virtual reality) and studies with methodological different approaches (e.g. case studies) are not considered in this review. Moreover, even though we included different possible variations of the search terms, there may be studies that discuss AR under yet other terms, and which may therefore not have found their way into this review.

\section{References}

[1] Adam, M. and M. Pecorelli, "Recommendations in Augmented Reality Applications - The Effect of Customer Reviews and Seller Recommendations on Purchase Intention and Product Selection", in Twenty-Sixth European Conference on Information Systems (ECIS), Portsmouth, UK. 2018.

[2] Azuma, R.T., "A Survey of Augmented Reality", Presence: Teleoperators \& Virtual Environments, 6(4), 1997, pp. 355-385.

[3] Baier, D., A. Rese, and S. Schreiber, "Analyzing online reviews to measure augmented reality acceptance at the point of sale", in Successful Technological Integration for Competitive Advantage in Retail Settings, I. Lee and E. Pantano, Editors. 2015. IGI Global.

[4] Beck, M. and D. Crié, "I virtually try it... I want it! Virtual Fitting Room: A tool to increase on-line and off-line exploratory behavior, patronage and purchase intentions", Journal of Retailing and Consumer Services, 40, 2018, pp. 279-286.

[5] Bonnin, G., "The Roles of Perceived Risk, Attractiveness of the Online Store and Familiarity with AR in the Influence of AR on Patronage Intention", Journal of Retailing and Consumer Services, 52, 2020, p. 101938.

[6] Bottani, E. and G. Vignali, "Augmented Reality Technology in the Manufacturing Industry: A Review of the Last Decade", IISE Transactions, 51(3), 2019, pp. 284-310.

[7] Bower, M., C. Howe, N. McCredie, A. Robinson, and D. Grover, "Augmented Reality in Education - Cases, Places and Potentials", Educational Media International, 51(1), 2014, pp. 1-15.

[8] Boyd, D.E. and B. Koles, "Virtual Reality and its Impact on B2B Marketing: A Value-in-use Perspective", Journal of Business Research, 100, 2019, pp. 590-598.

[9] Brengman, M., K. Willems, and H. van Kerrebroeck, "Can't touch this: the impact of augmented reality versus touch and non-touch interfaces on perceived ownership", Virtual Reality, 23(3), 2019, pp. 269-280.

[10] Brereton, P., B.A. Kitchenham, D. Budgen, M. Turner, and M. Khalil, "Lessons from applying the systematic literature review process within the software engineering domain", Journal of systems and software, 80(4), 2007, pp. 571-583.

[11] Craig, A.B., Understanding augmented reality: Concepts and applications, Morgan Kaufmann, Waltham, MA, 2013.
[12] Dacko, S.G., "Enabling Smart Retail Settings via Mobile Augmented Reality Shopping Apps", Technological Forecasting and Social Change, 124, 2017, pp. 243-256.

[13] Davis, F.D., "Perceived Usefulness, Perceived Ease of Use, and User Acceptance of Information Technology", MIS Quarterly, 13(3), 1989, pp. 319-340.

[14] Dunleavy, M., C. Dede, and R. Mitchell, "Affordances and Limitations of Immersive Participatory Augmented Reality Simulations for Teaching and Learning", Journal of science Education and Technology, 18(1), 2009, pp. 7-22.

[15] Fan, X., Z. Chai, N. Deng, and X. Dong, "Adoption of Augmented Reality in Online Retailing and Consumers' Product Attitude: A Cognitive Perspective", Journal of Retailing and Consumer Services, 53, 2020, p. 101986.

[16] Galar, D. and U. Kumar, "Maintenance Decision Support Systems", in eMaintenance. 2017. Elsevier.

[17] Hamari, J., A. Malik, J. Koski, and A. Johri, "Uses and Gratifications of Pokémon Go: Why do People Play Mobile Location-based Augmented Reality Games?", International Journal of Human-Computer Interaction, 35(9), 2019, pp. 804-819.

[18] Heller, J., M. Chylinski, K. de Ruyter, D. Mahr, and D.I. Keeling, "Let me imagine that for you: Transforming the retail frontline through augmenting customer mental imagery ability", Journal of Retailing, 95(2), 2019, pp. 94114.

[19] Heller, J., M. Chylinski, K. de Ruyter, D. Mahr, and D.I. Keeling, "Touching the Untouchable: Exploring MultiSensory Augmented Reality in the Context of Online Retailing", Journal of Retailing, 95(4), 2019, pp. 219-234.

[20] Herz, M. and P.A. Rauschnabel, "Understanding the Diffusion of Virtual Reality Glasses: The Role of Media, Fashion and Technology", Technological Forecasting and Social Change, 138, 2019, pp. 228-242.

[21] Hilken, T., D.I. Keeling, K. de Ruyter, D. Mahr, and M. Chylinski, "Seeing Eye to Eye: Social Augmented Reality and Shared Decision Making in the Marketplace", Journal of the Academy of Marketing Science, 48(2), 2020, pp. 143-164.

[22] Hilken, T., K. de Ruyter, M. Chylinski, D. Mahr, and D.I. Keeling, "Augmenting the Eye of the Beholder: Exploring the Strategic Potential of Augmented Reality to Enhance Online Service Experiences", Journal of the Academy of Marketing Science, 45(6), 2017, pp. 884-905.

[23] Huang, T.-L., "Psychological Mechanisms of Brand Love and Information Technology Identity in Virtual Retail Environments", Journal of Retailing and Consumer Services, 47, 2019, pp. 251-264.

[24] Huang, T.-L. and S. Liao, "A Model of Acceptance of Augmented-Reality Interactive Technology: The Moderating Role of Cognitive Innovativeness", Electronic Commerce Research, 15(2), 2015, pp. 269-295.

[25] Javornik, A., "'It's an illusion, but it looks real!'Consumer affective, cognitive and behavioural responses to augmented reality applications", Journal of Marketing Management, 32(9-10), 2016, pp. 987-1011.

[26] Javornik, A., "Augmented Reality: Research Agenda for Studying the Impact of its Media Characteristics on Consumer Behaviour", Journal of Retailing and Consumer Services, 30, 2016, pp. 252-261. 
[27] Javornik, A., Y. Rogers, A.M. Moutinho, and R. Freeman, "Revealing the Shopper Experience of Using a "Magic Mirror" Augmented Reality Make-Up Application", in Proceedings of the 2016 ACM Conference on Designing Interactive Systems - DIS '16, M. Foth, W. Ju, R. Schroeter, and S. Viller, Editors, Brisbane, Australia. 2016. ACM Press: New York, USA.

[28] Kitchenham, B., "Procedures for Performing Systematic Reviews", Keele, UK, Keele University, 33(2004), 2004, pp. 1-26.

[29] Laato, S., S. Hyrynsalmi, S. Rauti, A.N.M. Islam, and T.H. Laine, "Location-based Games as Exergames From Pokémon to the Wizarding World", International Journal of Serious Games, 7(1), 2020, pp. 79-95.

[30] Laato, S., T. Pietarinen, S. Rauti, M. Paloheimo, N. Inaba, and E. Sutinen, "A Review of Location-based Games: Do They All Support Exercise, Social Interaction and Cartographical Training?", in Proceedings of the 11th International Conference on Computer Supported Education, Heraklion, Crete, Greece. 2019.

[31] Lu, Y. and S. Smith, "Augmented Reality E-Commerce System: A Case Study", Journal of computing and information science in engineering, 10(2), 2010.

[32] Masood, T. and J. Egger, "Augmented Reality in Support of Industry 4.0 - Implementation Challenges and Success Factors", Robotics and Computer-Integrated Manufacturing, 58, 2019, pp. 181-195.

[33] Massetti, B., "An Empirical Examination of the Value of Creativity Support Systems on Idea Generation", MIS Quarterly, 20(1), 1996, pp. 83-97.

[34] McLean, G. and A. Wilson, "Shopping in the Digital World: Examining Customer Engagement Through Augmented Reality Mobile Applications", Computers in Human Behavior, 101, 2019, pp. 210-224.

[35] Morillo, P., J.M. Orduña, S. Casas, and M. Fernández, "A Comparison Study of AR Applications Versus PseudoHolographic Systems as Virtual Exhibitors for Luxury Watch Retail Stores", Multimedia Systems, 25(4), 2019, pp. 307-321.

[36] Moriuchi, E., V.M. Landers, D. Colton, and N. Hair, "Engagement With Chatbots Versus Augmented Reality Interactive Technology in E-Commerce", Journal of Strategic Marketing, 105(11), 2020, pp. 1-15.

[37] Morschheuser, B., M. Riar, J. Hamari, and A. Maedche, "How Games Induce Cooperation? A Study on the Relationship Between Game Features and We-Intentions in an Augmented Reality Game", Computers in Human Behavior, 77, 2017, pp. 169-183.

[38] Pantano, E., A. Rese, and D. Baier, "Enhancing the Online Decision - Making Process by Using Augmented Reality: A Two Country Comparison of Youth Markets", Journal of Retailing and Consumer Services, 38, 2017, pp. 81-95.

[39] Park, M. and J. Yoo, "Effects of Perceived Interactivity of Augmented Reality on Consumer Responses: A Mental Imagery Perspective", Journal of Retailing and Consumer Services, 52, 2020, p. 101912.

[40] Poushneh, A., "Augmented Reality in Retail: A TradeOff Between User's Control of Access to Personal Information and Augmentation Quality", Journal of Retailing and Consumer Services, 41, 2018, pp. 169-176.
[41] Poushneh, A. and A.Z. Vasquez-Parraga, "Discernible Impact of Augmented Reality on Retail Customer's Experience, Satisfaction and Willingness to Buy", Journal of Retailing and Consumer Services, 34, 2017, pp. 229234

[42] Rese, A., D. Baier, A. Geyer-Schulz, and S. Schreiber, "How augmented reality apps are accepted by consumers: A comparative analysis using scales and opinions", Technological Forecasting and Social Change, 124, 2017, pp. 306-319.

[43] Riar, M., B. Morschheuser, J. Hamari, and R. Zarnekow, "How Game Features Give Rise to Altruism and Collective Action? Implications for Cultivating Cooperation by Gamification", Proceedings of the 53rd Hawaii International Conference on System Sciences, 2020, pp. 695704.

[44] Smink, A.R., S. Frowijn, E.A. van Reijmersdal, G. van Noort, and P.C. Neijens, "Try Online before you buy: How does shopping with augmented reality affect brand responses and personal data disclosure", Electronic Commerce Research and Applications, 35, 2019, p. 100854.

[45] Spreer, P. and K. Kallweit, "Augmented Reality in Retail: Assessing the Acceptance and Potential for Multimedia Product Presentation at the PoS", Transactions on Marketing Research, 1(1), 2014, pp. 20-35.

[46] Steuer, J., "Defining Virtual Reality: Dimensions Determining Telepresence", Journal of communication, 42(4), 1992, pp. 73-93.

[47] Suh, A. and J. Prophet, "The State of Immersive Technology Research: A Literature Analysis", Computers in Human Behavior, 86, 2018, pp. 77-90.

[48] Tarafdar, P., A. Leung, W.T. Yue, and I. Bose, "Impact of Immersive Interface Design on Consumer Perceptions during Online Product Presentation", in Fortieth International Conference on Information Systems (ICIS), Munich. 2019.

[49] van Esch, P., D. Arli, M.H. Gheshlaghi, V. Andonopoulos, T. von der Heidt, and G. Northey, "Anthropomorphism and Augmented Reality in the Retail Environment", Journal of Retailing and Consumer Services, 49, 2019, pp. 35-42.

[50] Wu, H.-K., S.W.-Y. Lee, H.-Y. Chang, and J.-C. Liang, "Current Status, Opportunities and Challenges of Augmented Reality in Education", Computers \& education, 62, 2013, pp. 41-49.

[51] Xi, N. and J. Hamari, "VR Shopping: A Review of Literature", in Twenty-fifth Americas Conference on Information Systems (AMCIS), Cancún, Mexico, 2019.

[52] Yim, M.Y.-C., S.-C. Chu, and P.L. Sauer, "Is Augmented Reality Technology an Effective Tool for E-Commerce? An Interactivity and Vividness Perspective", Journal of Interactive Marketing, 39, 2017, pp. 89-103.

[53] Zhang, T., W.Y.C. Wang, L. Cao, and Y. Wang, "The Role of Virtual Try-on Technology in Online Purchase Decision from Consumers' Aspect", Internet Research, 2019, pp. 529-551.

[54] Zhao, X., C. Shi, X. You, and C. Zong, "Analysis of Mental Workload in Online Shopping: Are Augmented and Virtual Reality Consistent?", Frontiers in psychology, 8, 2017, p. 71. 